\title{
Efficient Silicon Solar Cells Fabricated with a Low Cost Spray Technique
}

\author{
Oleksandr Malik and F. Javier De la Hidalga-W. \\ National Institute for Astrophysics, Optics and Electronics (INAOE) \\ Mexico
}

\section{Introduction}

Since the 1960s, studies of transparent and highly conducting semiconductor metal oxide films, such as tin-doped indium oxide (ITO) and fluorine-doped tin oxide (FTO), have attracted the interest of many researches due to their wide applicability in both industry and research, such as transparent heat reflecting films, gas sensors, protective coatings, and heterojunction solar cells. Excellent reviews of the subject can be found in the literature (Hamberg \& Granquist, 1986, Granquist, 1993, Hartnagel et al, 1995, Dawar \& Joshi, 2004). Several methods such as chemical vapour deposition, vacuum evaporation, sputtering techniques, magnetron sputtering, ion implantation, ion-beam sputtering, and spraying techniques have been tried out to fabricate coatings for the oxide materials (Dawar \& Joshi, 2004). This chapter is intended to be a comprehensive review of the original results in the field of fabrication of ITO and FTO films by spray pyrolysis technique, as well as their applications for the fabrication of efficient silicon ( $\mathrm{Si}$ ) monocrystalline solar cells and modules with a low fabrication cost. Since the end of the 1970s, such solar cells have attracted the attention of the scientific community because of their fabrication simplicity (DuBow et al., 1976, Manifacier \& Szepessy, 1977, Feng at al., 1979, Malik et all., 1979, 1980). It has been shown that those metal oxide films deposited on the silicon surface form heterojunctions, which at a first approximation, can be considered as Schottky "transparent" metal-semiconductor (MS) contacts due to the degeneracy of the electron gas occurring in the n-type highly conducting transparent metal oxide films, such as ITO and FTO. Depending on the method used for the deposition of the films and the type of the silicon substrate conductivity, such contact can work as a rectifier and the surface-barrier solar cell can be designed based on it. Thus, films deposited in vacuum on the p-silicon surface form rectifying contacts (DuBow et al., 1976), while electron-beam (Feng at al., 1979), whereas sprayed films deposited on n-type silicon form rectifying contacts (Manifacier \& Szepessy, 1977, Malik et all., 1979). This phenomenon occurs because of the difference in electron affinity of the ITO and FTO films fabricated with the methods mentioned above. Further studies have shown that ITO/Si and FTO/Si solar cells operate almost always as majoritycarriers MS or metal-insulator-semiconductor (MIS) diodes. The formation of a very thin $\mathrm{SiO}_{x}$ layer between the metal oxide film and the silicon leads to an increasing efficiency of the solar cells based on MS contacts (Ashok et al., 1980). However, if the potential barrier at the silicon surface is very high, an inversion p-n layer is formed at the silicon surface. In this case the properties of these solar cells will be similar to those of solar cells based on 
metallurgical p-n junctions obtained by diffusion of dopants in a silicon substrate. This was demonstrated with ITO/Si structures fabricated by sputtering of the ITO film on a p-type silicon substrate (DuBow et al., 1976), where the solar cells operated as minority-carriers (or p-n) diodes. On the other hand, numerous published works have shown that solar cells fabricated on n-type silicon operate only as majority (MS or MIS) diodes (Nagatomo et al., $1979,1982)$. Nevertheless, in this work we show that combining a special treatment of the silicon surface with the electro-physical properties of the spray deposited films allows for the fabrication of inversion $\mathrm{p}-\mathrm{n}$ solar cells based on $\mathrm{n}$-type silicon substrates.

\section{Fabrication of ITO and FTO films by spray pyrolysis}

The spray pyrolysis technique was used for the deposition of thin ITO and FTO films on glass and sapphire substrates in order to investigate their structural, electric, and optical properties. A $10 \Omega$-cm n-type (100)-oriented silicon substrate, whose surface was chemically cleaned and specially treated, was used for the fabrication of the solar cells. The glass apparatus (atomizer) was designed in such a way that small-size droplets were obtained. The substrates were mounted on a heater covered with a carbon disk in order to assure a uniform temperature, and the spraying was conducted using compressed air. Periodical cycles of the deposition with durations of $1 \mathrm{sec}$ and intervals of $5 \mathrm{sec}$ were employed to prevent a rapid substrate cooling. Deposition rate was high, about $200 \mathrm{~nm} / \mathrm{min}$.

\subsection{Deposition of ITO films}

For the ITO films deposition, $13.5 \mathrm{mg}$ of $\mathrm{InCl}_{3}$ were dissolved in $170 \mathrm{ml}$ of 1:1 water and ethylic alcohol mixture, with an addition of $5 \mathrm{ml}$ of $\mathrm{HCl}$. Different ratios of $\mathrm{Sn} / \mathrm{In}$ achieved in the ITO films were controlled by adding in the solution a calculated amount of tin chloride $\left(\mathrm{SnCl}_{4} * 5 \mathrm{H}_{2} \mathrm{O}\right)$. The substrate temperature was controlled with a thermocouple at a value of $480 \pm 5{ }^{\circ} \mathrm{C}$. The optimal distance from the atomizer to the substrate and the compressed air pressure were $25 \mathrm{~cm}$ and $1.4 \mathrm{~kg} / \mathrm{cm}^{2}$, respectively. We obtained a high deposition rate of about $200 \mathrm{~nm} / \mathrm{min}$.

\subsection{Deposition of FTO films}

The precursors for the deposition of the FTO film were prepared based on $0.2 \mathrm{M}$ alcoholic solutions of $\mathrm{SnCl}_{4} * 5 \mathrm{H}_{2} \mathrm{O}$ with different content of $\mathrm{NH}_{4} \mathrm{~F}$ for obtaining different $\mathrm{F} / \mathrm{Sn}$ ratio in the films. The remaining deposition parameters were the same as those used for depositing the ITO films.

\subsection{Characterization equipment and methods}

The film thickness was measured with an Alpha Step 200 profilometer. The electrical resistivity, Hall mobility and carrier concentration were measured at room temperature using the van der Pauw method. Hall effect parameters were measured using a magnetic field of 0.25 Tesla. The optical transmission spectra were obtained with a spectrophotometer. The structural characterization was carried out with an X-ray diffractometer operating in the Bragg-Brentano $\Theta-\Theta$ geometry with $\mathrm{Cu} \mathrm{K}_{\mathrm{a}}$ radiation. A JSPM 5200 atomic force microscope was used to study the film surfaces. The chemical composition of the films was determined using an UHV system of VG Microtech ESCA2000 Multilab with an Al- $\mathrm{K}_{\alpha}$ X-ray source $(1486.6 \mathrm{eV})$ and a CLAM4 MCD analyzer. 


\section{Brief description of the film properties}

\subsection{Tin-doped indium oxide (ITO) films}

The X-ray diffraction (XRD) measurements shown in Figure 1 indicate that all deposited ITO films, with thickness 160-200 nm and fabricated from the chemical solutions with different $\mathrm{Sn} / \mathrm{In}$ ratio, present a cubic bixebyte structure in a polycrystalline configuration with a (400) preferential grain orientation.

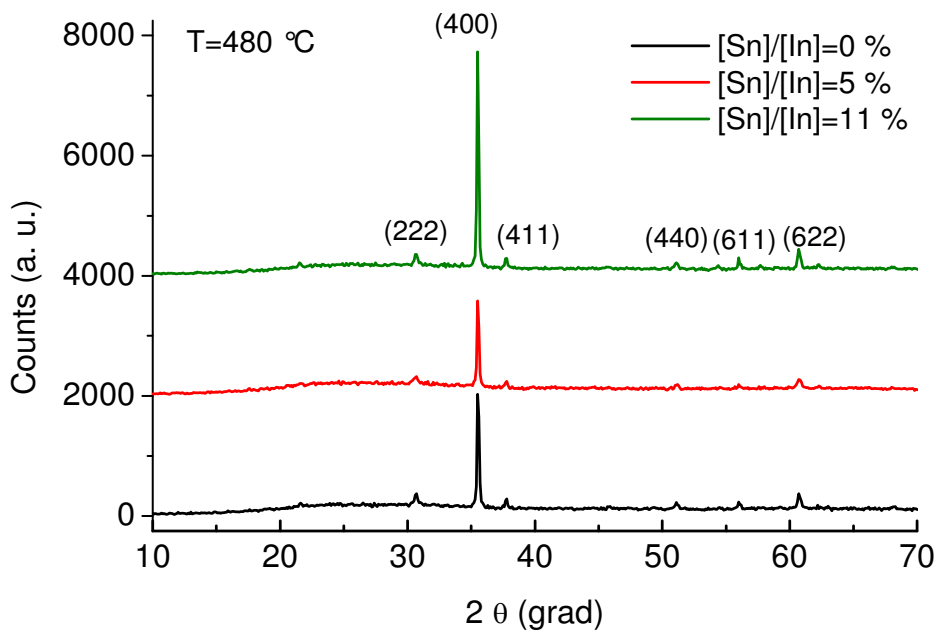

Fig. 1. XRD spectra of the ITO films fabricated from precursors with different $\mathrm{Sn} / \mathrm{In}$ ratio

The average size of the grains, $30-50 \mathrm{~nm}$, was determined using the classical Debye-Scherrer formula from the half-wave of the (400) reflections of the XRD patterns

A surface roughness about $30 \mathrm{~nm}$ was determined from images of the films surfaces obtained with the atomic force microscope (Figure 2).
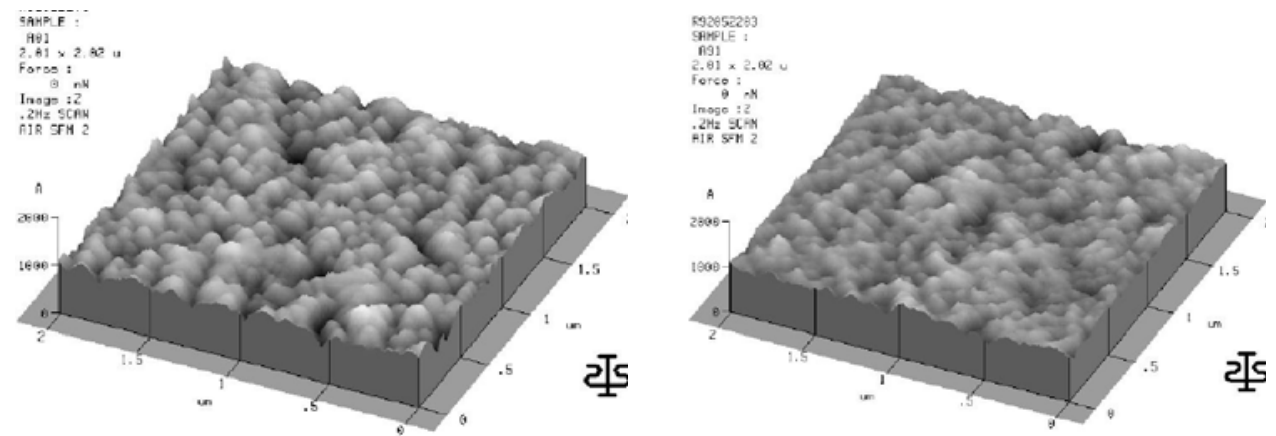

Fig. 2. AFM images of the $\operatorname{In}_{2} \mathrm{O}_{3}$ film (left) and the ITO film with $5 \% \mathrm{Sn} / \mathrm{In}$ (right)

Figures 3 and 4 show the dependence of electric parameters of the spray deposited ITO film on the ratio $\mathrm{Sn} / \mathrm{In}$. The sheet resistance $\mathrm{R}_{\mathrm{s}}$ shown in Figure 3 presents a minimum of $12 \Omega / \square$ the films prepared from the solution with a $5 \% \mathrm{Sn} / \mathrm{In}$ ratio. 


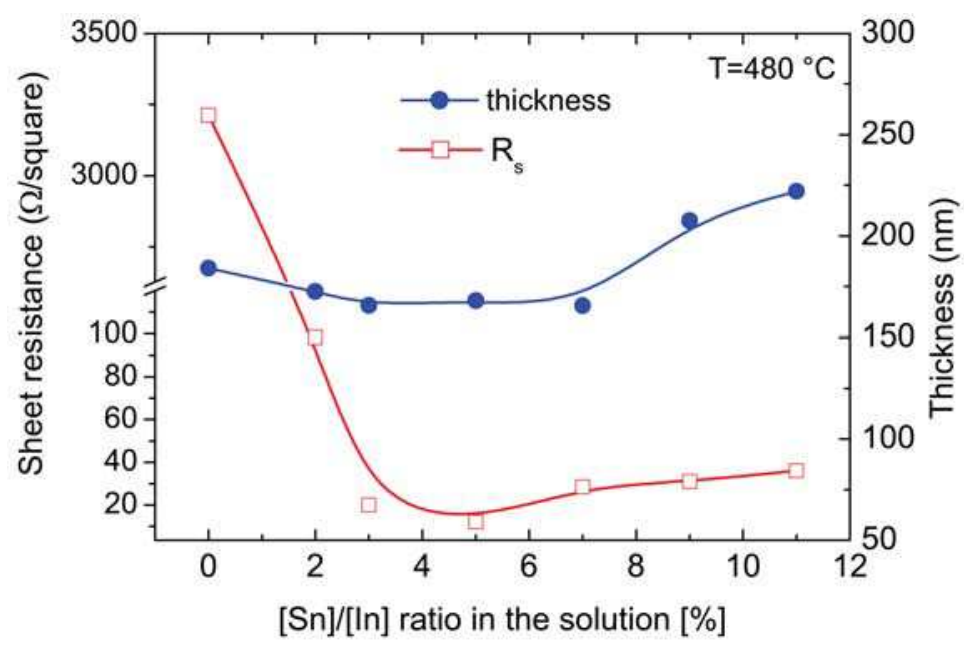

Fig. 3. The sheet resistance as a function of the $\mathrm{Sn} / \mathrm{In}$ ratio in the precursor used for the film deposition. The thicknesses of the films are also shown

The minimal value of resistivity obtained for the films deposited for the solution with $5 \%$ $\mathrm{Sn} / \mathrm{In}$ ratio is $2 \times 10^{-4} \Omega-\mathrm{cm}$. The variation of mobility and carrier concentration as a function of the $\mathrm{Sn} / \mathrm{In}$ ratio are shown in Figure 4.

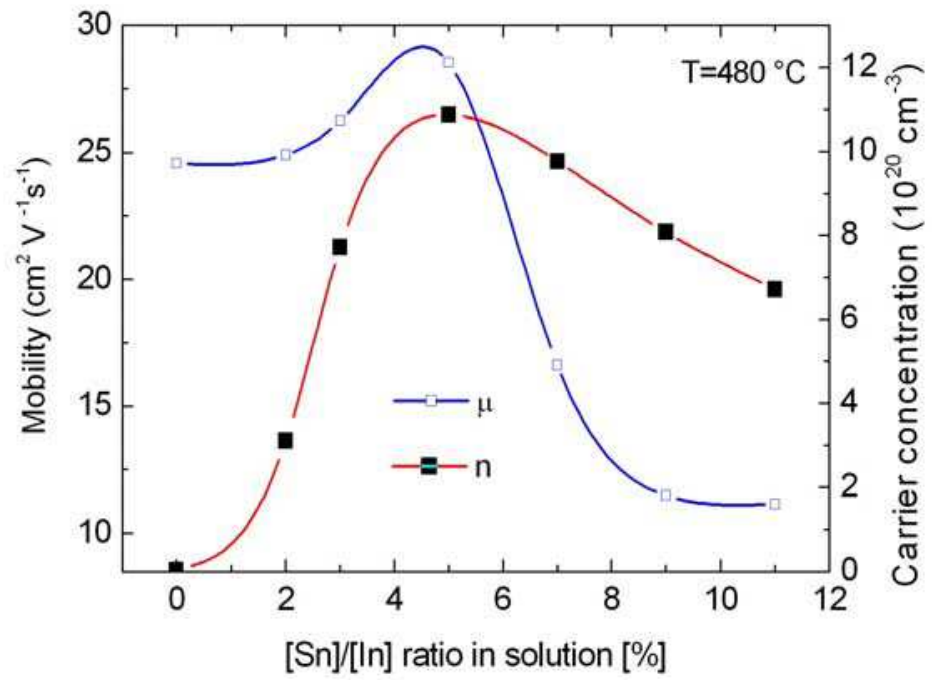

Fig. 4. Dependence of mobility $(\mu)$ and carrier concentration (n) on the Sn/In ratio

Figure 5 shows the optical transmission spectra for the ITO films spray-deposited on a sapphire substrate as a function of the wavelength for solutions with different $\mathrm{Sn} / \mathrm{In}$ contents.

The use sapphire substrates allow for determining the optical energy gap of the ITO films by extrapolating the linear part of $\alpha^{2}(h v)$ curves to $\alpha^{2}=0$, where $\alpha$ is the absorption coefficient. 


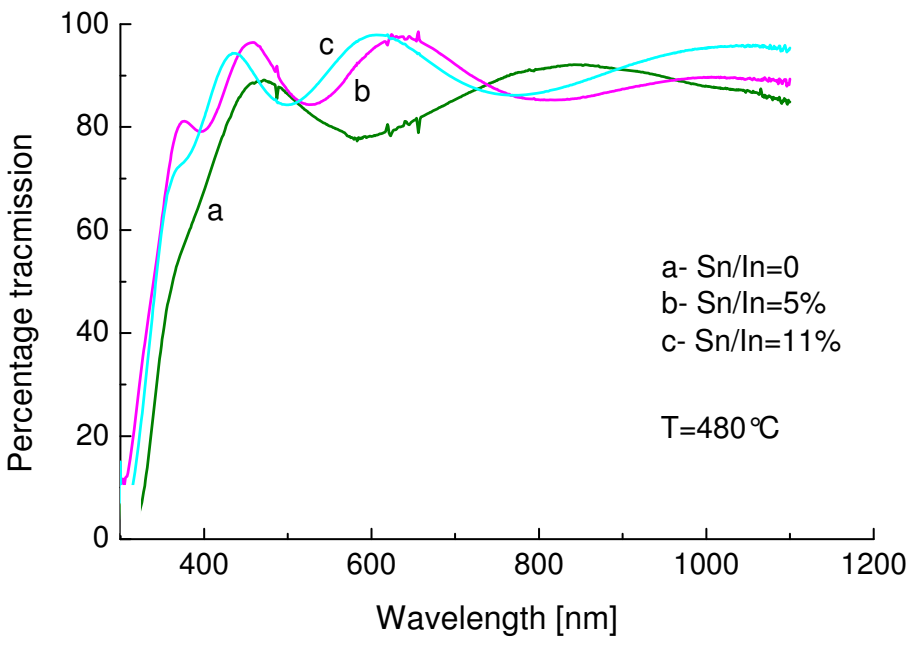

Fig. 5. Optical transmission spectra for the ITO films spray-deposited for different precursors as a function of the wavelength

The optical gap increases with the carrier concentration, corresponding to the well known Burstein-Moss shift. For the Ito films fabricated using the solution with a 5\% Sn/In ratio this shift is $0.48 \mathrm{eV}$, and the optical gap is $4.2 \pm 0.1 \mathrm{eV}$. Such high value for the optical gap offers transparency in the far ultraviolet range, which is important for the application of these films in solar cells.

Because of the opposite dependence of the conductivity $(\sigma)$ and transmission $(T)$ on the thickness $(t)$ of the ITO, both parameters need to be optimized.

A comparison of the performance for different films is possible using the $\phi_{\mathrm{TC}}=\mathrm{T}^{10} / \mathrm{R}_{\mathrm{S}}=\sigma \mathrm{t}$ $\exp (-10 \alpha t)$ figure of merit (Haacke, 1976). Table 1 compares the values of $\phi_{\mathrm{TC}}$ for the spray deposited ITO films reported in this work with some results obtained by other authors using different deposition techniques.

\begin{tabular}{|l|c|c|c|l|}
\hline Process & $\mathrm{R}_{\mathrm{s}}, \Omega / \square$ & $\mathrm{T}(\%)$ & $\phi_{\mathrm{TC},}\left(\Omega^{-1}\right) \times 10^{-3}$ & \multicolumn{1}{|c|}{ Author } \\
\hline spray & 26.0 & 90 & 13.4 & Gouskov, 1983. \\
\hline spray & 9.34 & 85 & 21.0 & Vasu et al., 1990 \\
\hline spray & 10.0 & 90 & 34.9 & Manifacier, 1981 \\
\hline spray & 4.4 & 85 & 44.7 & Saxena, 1984 \\
\hline sputtering & 12.5 & 95 & 47.9 & Theuwissen, 1984 \\
\hline evaporation & 25.0 & 98 & 32.6 & Nath, 1980 \\
\hline spray & 12.0 & 93.7 & 43.5 & Present work \\
\hline
\end{tabular}

Table 1. Comparison of the values of $\phi_{\mathrm{TC}}$ for ITO films

\subsection{Fluorine-doped tin oxide (FTO) films}

The X-ray diffraction (XRD) measurements indicate that all the spray-deposited FTO films present a tetragonal rutile structure in a polycrystalline configuration with a (200) 
preferential grain orientation. The XRD spectra of the FTO films fabricated using precursors with different F/Sn ratios are shown in Figure 6.

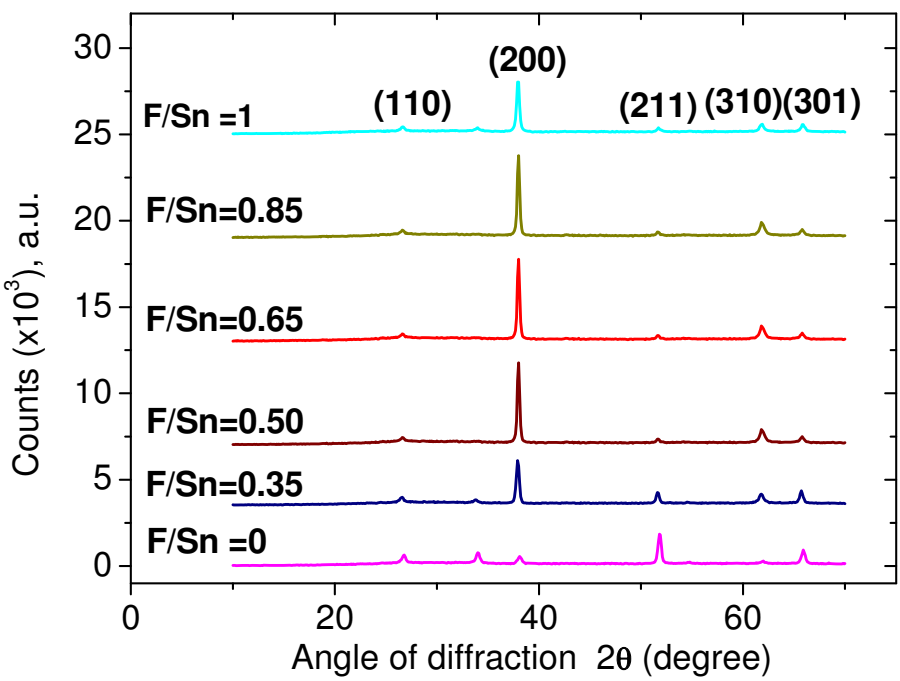

Fig. 6. The XRD spectra for the FTO films fabricated using precursors with different F/Sn ratio

The surface morphology of the films fabricated using precursors with different F/Sn ratio, and obtained with a scanning electron microscopy (SEM), is shown in Figure 7.

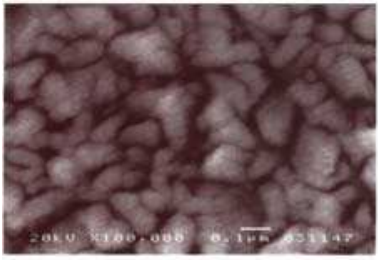

$\mathrm{F} / \mathrm{S} n=0$

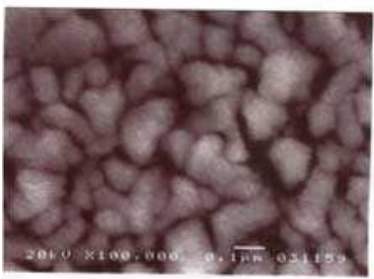

$\mathrm{F} / \mathrm{Sn}=\mathbf{0 . 6 5}$

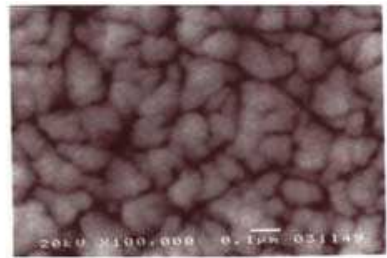

$\mathrm{F} / \mathrm{Sn}=\mathbf{0 . 3 5}$

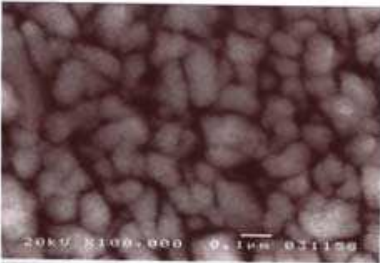

$\mathrm{F} / \mathrm{Sn}=\mathbf{0 . 8 5}$

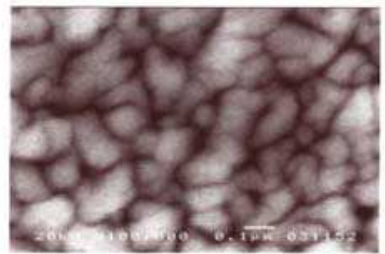

$\mathrm{F} / \mathrm{Sn}=\mathbf{0 . 5 0}$

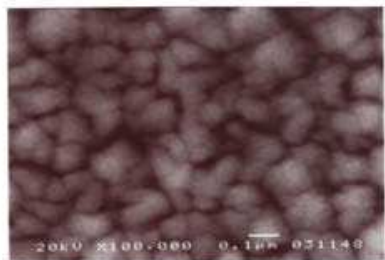

$\mathrm{F} / \mathrm{Sn}=1$

Fig. 7. The surface morphology obtained with a SEM for the films fabricated using precursors with different $\mathrm{F} / \mathrm{Sn}$ ratios

The dependence of the average value of the grain size on the F/Sn ratio shows a maximum $(\sim 40 \mathrm{~nm})$ for the films prepared using a precursor with $\mathrm{F} / \mathrm{Sn}=0.5$. The roughness variation 
obtained with atomic force microscope for the FTO film fabricated using solutions with different $\mathrm{F} / \mathrm{Sn}$ ratios presents a minimum of $8-9 \mathrm{~nm}$ at the $\mathrm{F} / \mathrm{Sn}=0.5$ ratio.

Figure 8 shows that the electrical characteristics also present some peculiarities for the films prepared using a precursor with this $\mathrm{F} / \mathrm{Sn}$ ratio.
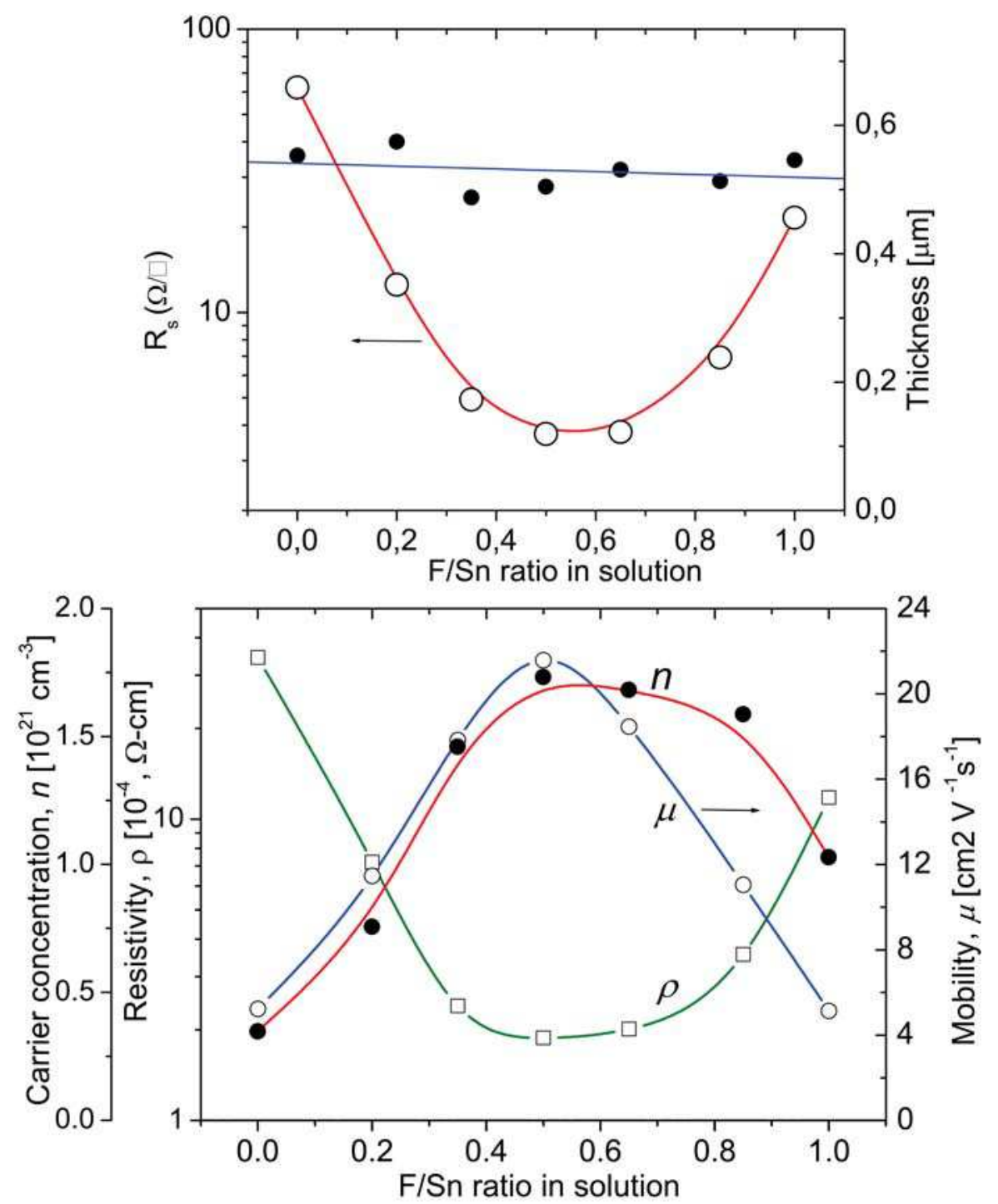

Fig. 8. Variation of the sheet resistance (above graph), resistivity $(\rho)$, mobility $(\mu)$ and carrier concentration (n) (below graph) for the FTO films fabricated using precursors with different $\mathrm{F} / \mathrm{Sn}$ ratios. The thicknesses of the films are also shown 

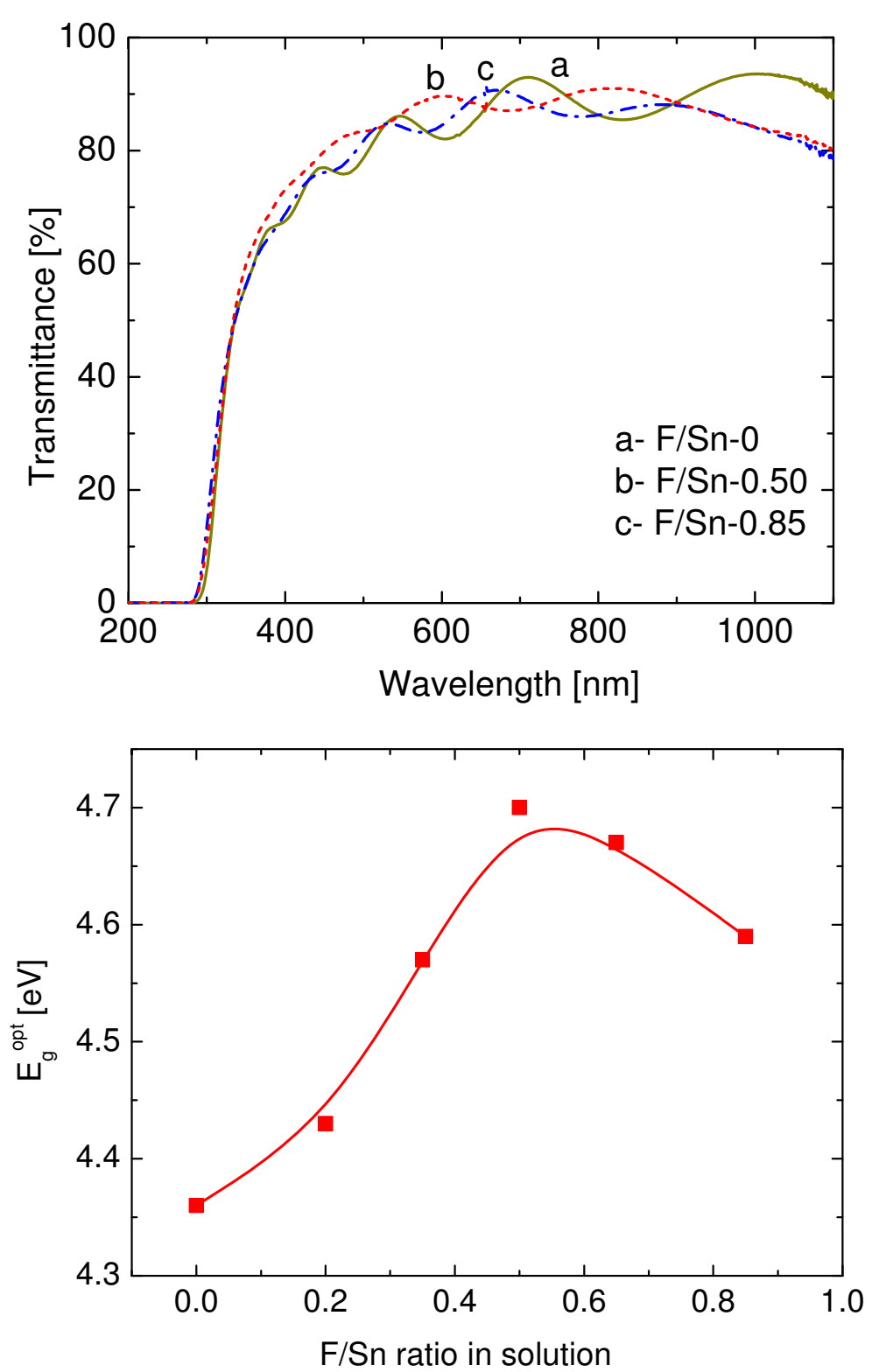

Fig. 9. Optical transmission (above graph) and dependence of the optical gap (below graph) for the FTO films fabricated using solutions with different F/Sn contents and spraydeposited on a glass substrate as a function of the wavelength

The optical energy gap (Fig. 9) was determined from the analysis of the absorption spectra for the films deposited on the sapphire substrate. The Burstein-Moss shift presents a 
maximum value of $0.6 \mathrm{eV}$ for the films fabricated using the precursor with $\mathrm{F} / \mathrm{Sn}=0.5$, which also corresponds to the highest electron concentration $\left(1.8 \times 10^{21} \mathrm{~cm}^{-3}\right)$. Figure 10 shows the $\Phi=T^{10} / R_{\mathrm{s}}$ figure of merit for the FTO films reported in this work.

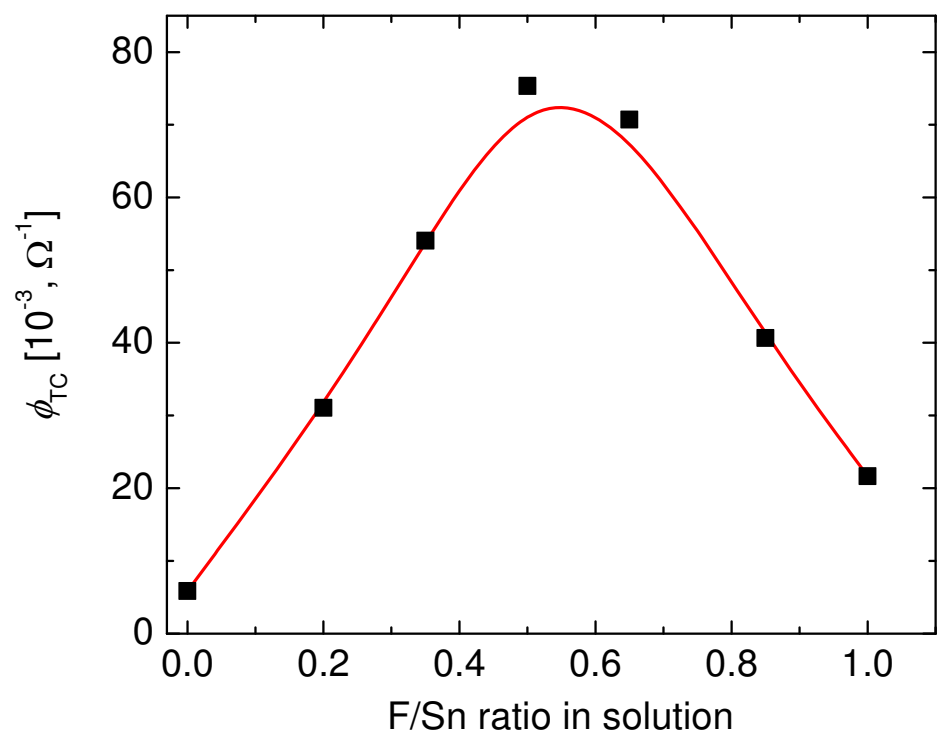

Fig. 10. Variation of the figure of merit $\Phi=T^{10} / R_{\mathrm{s}}$ versus the $\mathrm{F} / \mathrm{Sn}$ ratio used in the solution for the FTO films reported in this work

The value we obtained for this figure of merit was $\Phi=75 \times 10^{-3} \Omega^{-1}$ for the films prepared using a precursor with $\mathrm{F} / \mathrm{Sn}=0.5$; this is more than twice the value $\left(\Phi=35 \times 10^{-3} \Omega^{-1}\right)$ reported in the literature (Moholkar et al., 2007) for spray deposited FTO films.

\section{Solar cells based on ITO/n-Si heterojunctions}

\subsection{Physical model of the solar cells}

When the ITO (or FTO) film is deposited on the silicon surface, a metal-semiconductor contact-like is formed due to the metallic electric properties of the degenerated metal oxide. Ideally, the barrier height $\left(\varphi_{\mathrm{b}}\right)$ formed between the metal and the n-type semiconductor is determined by the difference between the metal (or in our case the metal oxide) work function $\left(\varphi_{\mathrm{M}}\right)$ and the electron affinity $\left(\chi_{\mathrm{s}}\right)$ in the semiconductor. Actually, the surface states present in the interface pin the Fermi level, which makes the barrier height less sensitive to the metal work function (Sze, 2007). The surface has to experiment a reconstruction due to the discontinuity of the lattice atoms on the surface. Each surface atom present a dangling bond and shares a dimer bond with its neighbor atom, thus giving place to surface states inside the Si band gap (Trmop, 1985).

Recently, it has been shown that the barrier height in a metal-silicon junction can take an almost ideal value if the n-Si surface is passivated with sulfur (Song, 2008). Also the opencircuit voltage of an $\mathrm{Al} /$ ultrathin $\mathrm{SiO}_{2} / \mathrm{n}$-Si solar cell (Fujiwara, 2003) was improved when the silicon surface was passivated by a cyanide treatment. 
In this chapter we will discuss the properties of the ITO/n-Si solar cells presenting extremely high values of the potential barrier at the silicon interface obtained by passivating the surface with a hydrogen-peroxide solution.

If the ITO film is deposited on cleared n-type silicon, the barrier height not exceeds $0.76 \mathrm{eV}$. For this value of the barrier height, the ITO/nSi heterojunctions fabricated on silicon substrates with a resistivity of a few $\Omega$-cm, operate as majority carrier devices, whose characteristics are well described by the Schottky theory. Usually, such type of devices present a high value for the dark current originated by the thermo-ionic mechanism, and the open circuit voltage for these structures designed as solar cells shows a sufficiently low value. The introduction of a very thin $(\sim 2 \mathrm{~nm})$ intermediate $\mathrm{SiO}_{\mathrm{x}}$ layer (Feng, 1979) decreases the dark current and increases the open-circuit voltage. However, the use of this approach to improve the characteristics of the surface-barrier solar cells requires a simultaneous and careful control of the intermediate oxide thickness. Furthermore, the thermal grown intermediate $\mathrm{SiO}_{x}$ layer always presents a positive fixed charge located at the $\mathrm{SiO}_{x} / \mathrm{Si}$ interface, which decreases the barrier height in the case of n-type silicon.

Using known data for the work function of ITO films deposited by spray pyrolysis, whose average value is reported as $5.0 \mathrm{eV}$ (Nakasa et al., 2005, Fukano, 2005), and the electron affinity of silicon as $4.05 \mathrm{eV}$, the ideal barrier height between ITO and n-type silicon is 0.95 $\mathrm{eV}$ according to the Mott-Schottky theory. After a treatment of the n-type silicon surface in the hydrogen-peroxide $\left(\mathrm{H}_{2} \mathrm{O}_{2}\right)$ solution with a controlled temperature $\left(60{ }^{\circ} \mathrm{C}\right)$ during 10 minutes, a barrier height of $0.9 \mathrm{eV}$ was obtained with capacitance-voltage measurements. This value exceeds by $0.14 \mathrm{eV}$ the barrier height obtained after the deposition of the ITO film on the silicon surface cleaned in $\mathrm{HF}$ without the treatment in an $\mathrm{H}_{2} \mathrm{O}_{2}$ solution.

It is worth discussing the possible reason for this increment of the barrier height after the treatment of the silicon surface, as well as the operation of the ITO/n-Si junctions with an extremely high barrier height. Obviously, a junction with such barrier height fabricated on the silicon substrates with moderate resistivity could behave as $p-n$ junctions, in which a surface p-layer is induced by the high surface band bending.

Such situation was obtained (Shewchun, 1980) in solar cells ITO/ultrathin $\mathrm{SiO}_{x} / \mathrm{p}-\mathrm{Si}$ structures. However, in this case the inversion of the conductivity type of the p-Si at the surface was caused by other factors, such as the low work function of the sputtered ITO film and the presence of positive charge at the $\mathrm{SiO}_{\mathrm{x}} / \mathrm{p}$-Si interface.

What is the physical reason for the increment of the barrier height in the ITO/n-Si heterojunctions after the treatment of the silicon substrate in heated $30 \% \mathrm{H}_{2} \mathrm{O}_{2}$ solutions? It has been shown (Verhaverbeke, 1997) that the treatment of the silicon in $\mathrm{H}_{2} \mathrm{O}_{2}$ leads to the growth of oxide on the silicon surface. The analysis shows that the main oxidant responsible for this oxide growth is the peroxide anion, $\mathrm{HO}_{2}^{-}$. It was also found that the oxide thickness is limited to a value around $0.8-1.0 \mathrm{~nm}$ due to the presence of localized negative charge $\left(\mathrm{HO}_{2}{ }^{-}\right)$at the silicon surface. From this point of view the $\mathrm{HO}_{2}{ }^{-}$at the silicon surface can play a double role. First, these ions can form a chemical composition with the silicon atoms having dangling bounds in the surface. This can be thought as a passivation of the silicon surface, which leads to an increment of the potential barrier during the formation of the ITO/Sl heterostructure. On the other hand, the negative charge of these ions can produce a band-bending $\left(\varphi_{s}\right)$ at the silicon surface due to an outflow of electrons under the influence of the electrostatic force. Under such conditions, the electron affinity $\left(\chi_{s}\right)$ of the silicon at the surface will be lower than that at the bulk by $\Delta \chi=\chi_{\mathrm{s}}-\varphi_{\mathrm{s}}$. The presence of a depletion layer at 
the silicon surface plays an important role for the formation of the potential barrier during the deposition of the ITO film. The barrier will prevent an electron flow from the silicon to the ITO film. The surface barrier between the ITO and the silicon will be formed by the flow of valence electrons from the silicon valence band into the ITO film, creating a hole excess at the silicon surface. Taking into account the initial band-bending at the silicon surface, the formation of an inversion layer is possible. As it was already mentioned, the experimentally determined barrier height at the ITO/Si interface is $0.9 \mathrm{eV}$. Schematically, the energy diagram of the ITO/n-Si heterojunction is shown in Figure 11.

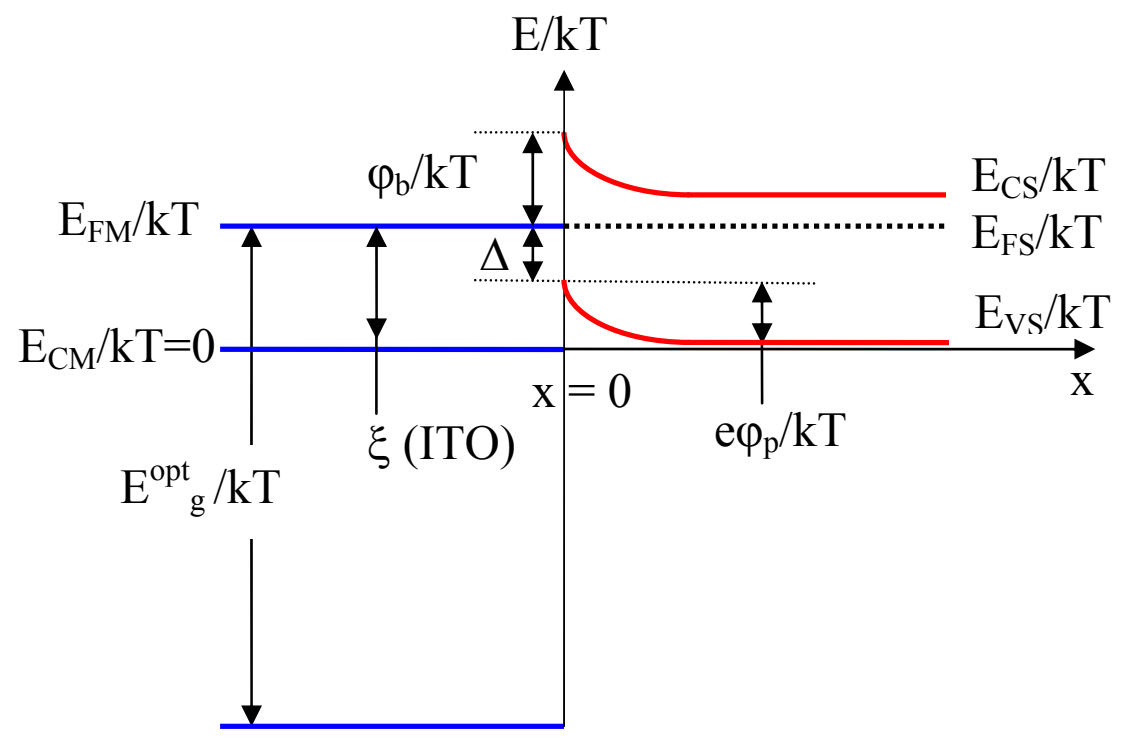

Fig. 11. Energy diagram (in $k T$ units) of the heavy doped ITO/n-Si heterojunction

For sake of simplicity, we do not show the very thin (around $1 \mathrm{~nm}$ ) intermediate $\mathrm{SiO}_{\mathrm{x}}$ layer present between the ITO film and the silicon, because at this thickness it does not present any effect on the electro-physical characteristics of the heterojunction. Since the heavily doped ITO film is a degenerated semiconductor, in which the Fermi level lies above the minimum of the conduction band, we can consider this ITO film as a "transparent metal." The inversion layer at the silicon interface appears when the barrier height $\varphi_{\mathrm{b}}$ is higher than one-half of the Si energy gap. If such inversion p-n junction were connected in a circuit, which source of holes would be present in order to form an inversion p-layer that complicates the current flow across the forward-biased structure working as a solar cell? To answer this question we calculated the number of empty energy states in the conduction band of a heavy doped ITO, which are available to accept the electrons transferred from the top of the silicon valence band located at a distance $\Delta$ below the Fermi level (Malik et al., 2006). The probability that an energy state $E$ below the Fermi level $E_{F M}$ in the degenerated ITO is empty was calculated using the Fermi-Dirac distribution. Using a barrier height $\varphi_{\mathrm{n}}=0.9 \mathrm{eV}, \Delta=0.3 \mathrm{eV}$, and three different values for $\left(\mathrm{E}_{\mathrm{FM}}-\mathrm{E}_{\mathrm{CM}}\right)$, which is the distance between the Fermi level an the conducting band of the ITO. This characterizes the degree of degeneration of the ITO film. The calculated number of empty states available to accept the 
electrons from the silicon valence band forming the additional amount of the holes is shown in Figure 12 as triangles. For comparison the number of empty states in the case of a gold/silicon contact with the same barrier height is also shown. For such calculations, the difference between the effective mass of electrons in the ITO and that in gold has been taken into account.

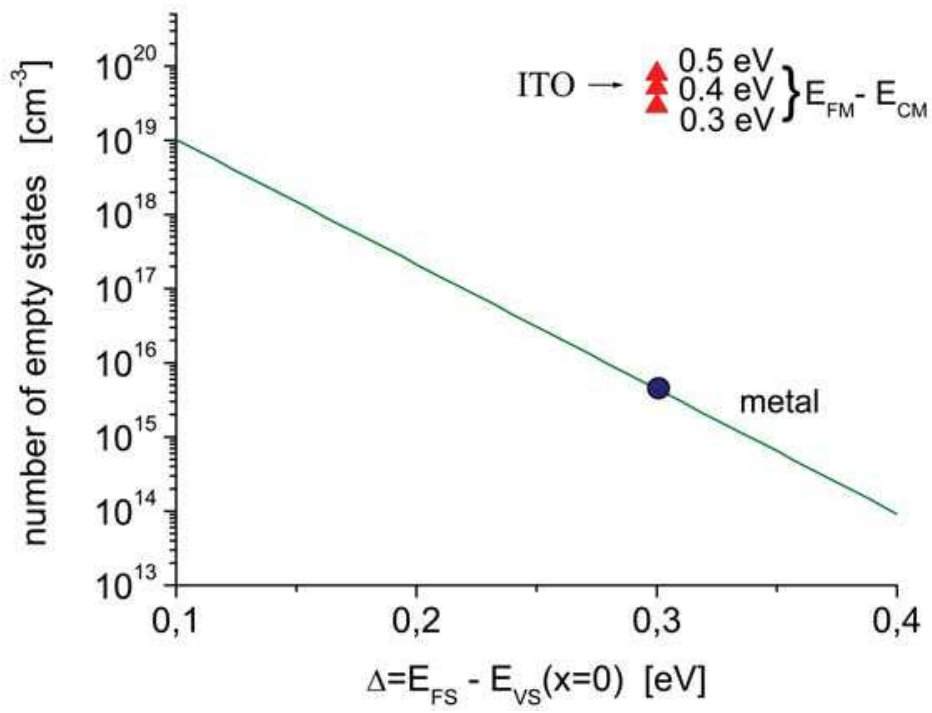

Fig. 12. Calculated number of empty states available to accept the electrons from the silicon valence band (Malik et al., 2006)

From the discussion presented above, and the amount of the calculated number of empty states in the ITO, leads to the important conclusion that a heavy doped ITO layer serves as an efficient source of holes necessary to form the inversion p-layer in the ITO/n-Si structures.

\subsection{Evidence of the inversion in the type conductivity in the ITO/n-Si heterostructures}

Based on the barrier height $(0.9 \mathrm{eV})$ obtained from the measured $\mathrm{C}-\mathrm{V}$ characteristics for the ITO/n-Si heterostructures on $10 \Omega$-cm monocrystalline silicon, one can discuss about the physical nature of such heterojunctions. Because the barrier height exceeds one half of the silicon band gap, the formation of an inversion p-layer at the silicon surface is obvious from the band diagram. To avoid any speculations on this issue and in order to present a clear evidence for the existence of a minority (hole) carrier transport in these heterojunctions, a bipolar transistor structure was fabricated on a $10 \Omega$-cm monocrystalline silicon substrate, in which the emitter and the collector areas, on opposite sides of the silicon substrate, were fabricated based on the ITO/n-Si junctions. The ITO film was deposited using the spray deposition technique described in section 2.1 followed by a photolithographic formation of the emitter and the collector areas. The treatment in the $\mathrm{H}_{2} \mathrm{O}_{2}$ solution described above was applied to the silicon substrate. An ohmic $\mathrm{n}^{+}$-contact (the base) was formed using local diffusion of phosphorous in the silicon substrate. The dependence of the collector current versus the collector-base voltage, using the emitter current as a parameter, are shown in 
Figure 13, together with the emitter injection efficiency of the ITO/n-Si/ITO transistor (Malik et al., 2004).
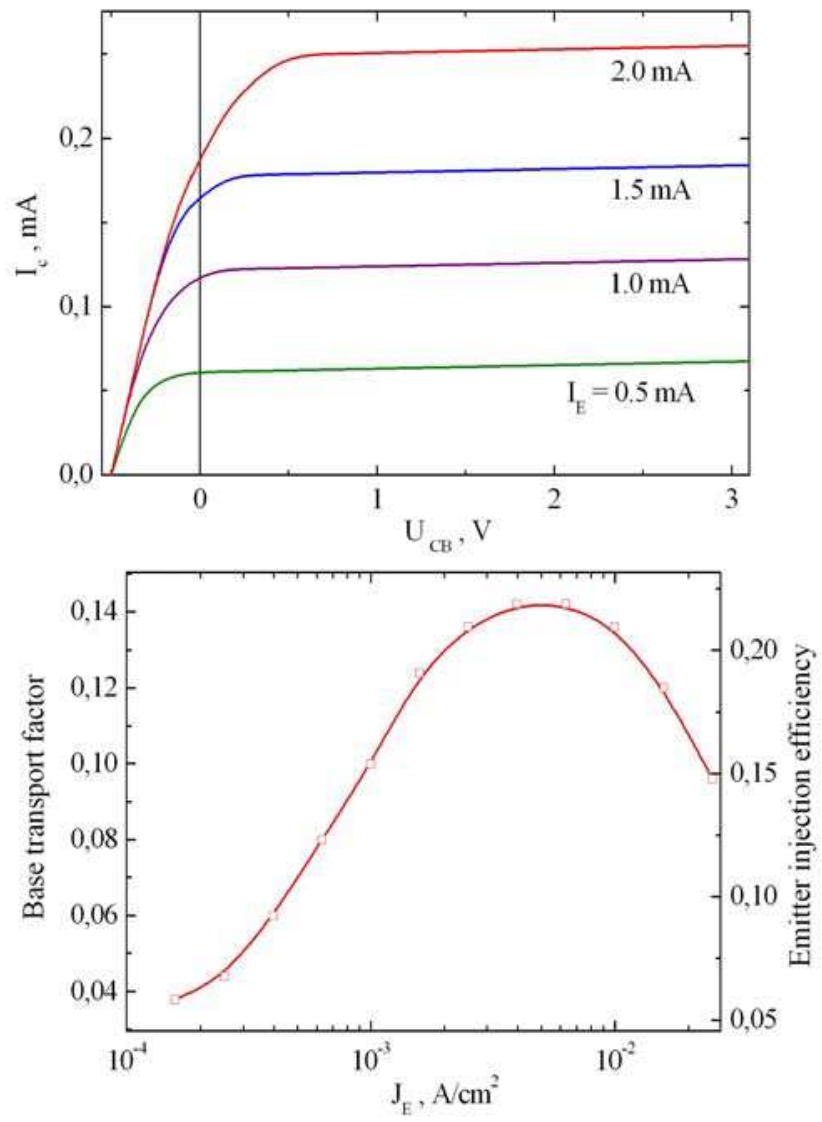

Fig. 13. Dependence of the collector current on the collector-base voltage (the emitter current is used as a parameter). The emitter injection efficiency of the ITO/n-Si/ITO transistor fabricated on a $10 \Omega$-cm silicon substrate is also shown. (Malik et al., 2004)

Hence, even in non-optimized transistors (wide base), an efficient hole injection of around 0.2 was observed. This is an obvious evidence of the existence of an inversion layer in the ITO/n-Si heterostructures with a barrier height of $0.9 \mathrm{eV}$. We can also present two indirect evidences of the p-n nature of the ITO/n-Si heterojunctions. The first one is based on the observation of an efficient radiation emission from the ITO/n-Si structures under a forward bias (Malik et al., 2004). In metal-semiconductor contacts operated as majority carriers' devices (described by the Schottky theory), the injection ratio does not exceed $10^{-4}$. Thus, an efficient electroluminescence, in contrast to our devices, is not possible to observe. The next evidence is based on the observed modulation of the conductivity in the forward-biased ITO/n-Si diodes fabricated on high resistivity silicon, which operate as p-i-n diodes. So, the $0.9 \mathrm{eV}$ barrier height belongs to an inversion ITO/n-Si heterojunction. This gives us the 
possibility to analyze theoretically such structures based on the well-known theory of p-n junctions.

\subsection{Limit of applicability of the p-n model for the ITO/n-Si solar cells}

Once we know the physical nature of the ITO/n-Si heterojunctions with extremely high potential barrier, it is possible to apply correctly the theory for their modelling, which is known as the theory of p-n based solar cells. The problem now is to find the range of resistivity of the silicon substrate on which the p-n theory can be applied to the ITO/n-Si heterojunction with extremely high potential barrier. Based on results published recently (Malik et al., 2008), the condition for strong inversion in the ITO/n-Si heterojunction requires that

$$
\varphi_{s} \geq 2\left(E_{F}-E_{i}\right)
$$

where

$$
E_{F}-E_{i}=k T \ln \left(N_{d} / n_{i}\right),
$$

$\varphi_{s}$ is the surface potential at the $\mathrm{Si} / \mathrm{SiO}_{\mathrm{x}}$ interface, $k$ is the Boltzmann constant, $T$ is the temperature, $n_{i}$ is the intrinsic carrier concentration, and $N_{\mathrm{d}}$ is the donor concentration in the n-Si substrate. On the other hand,

$$
\begin{gathered}
\varphi_{s}=\varphi_{b}-\left(E_{C}-E_{F}\right), \\
E_{C}-E_{F}=k T \ln \left(N_{C} / N_{d}\right),
\end{gathered}
$$

where $\varphi_{b}$ is the potential barrier for carriers from the ITO side of the structure, and $N_{C}$ is the effective density of states in the conduction band.

Moreover, the surface hole concentration is

$$
p_{s}(x=0)=\left(n_{i}^{2} / N_{d}\right) \exp \left(\varphi_{s} / k T\right)
$$

Combining equations (2)-(5), it is possible to obtain the surface concentration of the minority carriers at the $\mathrm{Si} / \mathrm{SiO}_{x}$ interface under strong inversion of the conductivity type:

$$
p_{s}(x=0)=\left(n_{i}^{2} / N_{C}\right) \exp \left(\varphi_{b} / k T\right) .
$$

This concentration depends only on the barrier height and not on $N_{\mathrm{d}}$. Figure 14 shows the two possible models in the space $p_{\mathrm{s}}(\mathrm{x}=0) / N_{\mathrm{d}}$ vs. $N_{\mathrm{d}}$ in the substrate for different barrier heights.

The two shaded areas are related to the two possible models: a Schottky model for $p_{\mathrm{s}}(\mathrm{x}=0) / N_{\mathrm{d}}<0.01$ and an induced $p-n$ junction, in which $p_{\mathrm{s}}(\mathrm{x}=0) / N_{\mathrm{d}}>10$. For instance, at a barrier height of $0.7 \mathrm{~V}$, the green line takes two intercepts: one with the border of the area that is related to the Schottky barrier model, and the other one with the border of the area that is valid for the $p-n$ inversion model. Thus, for $N_{d}>3 \times 10^{14} \mathrm{~cm}^{-3}$ the structures behave as Schottky-barrier structures, whereas the structures with $N_{\mathrm{d}}<4 \times 10^{13} \mathrm{~cm}^{-3}$, behave as $\mathrm{p}-\mathrm{n}$ 


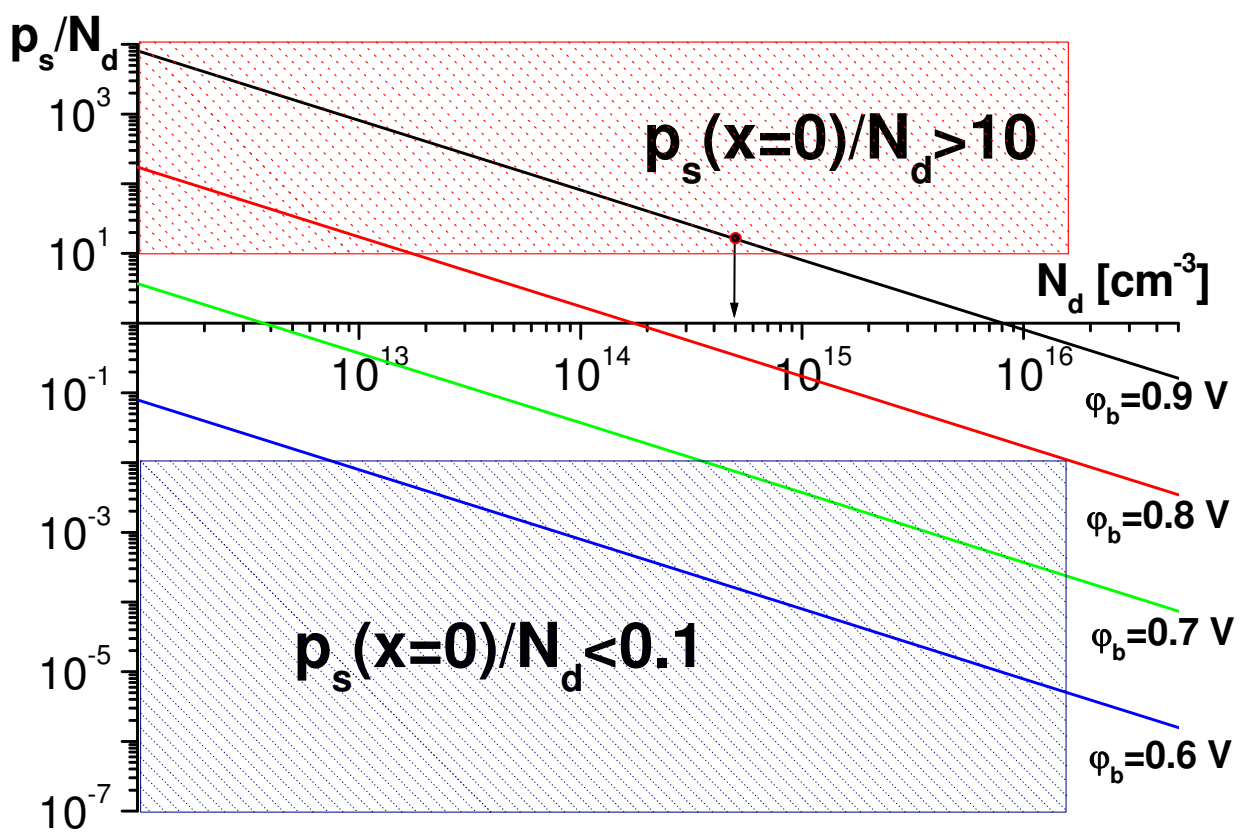

Fig. 14. Schematically representation of two possible models of the ITO/n-Si heterojunction in coordinates of $p_{\mathrm{s}}(\mathrm{x}=0) / N_{\mathrm{d}} \mathrm{vs}$. concentration $N_{\mathrm{d}}$ in the silicon substrate. The different barrier height serves as a parameter (Malik et al., 2008)

junctions. With the potential barrier height of $0.9 \mathrm{eV}$ achieved in this work, the structures may be considered as a symmetrical $p-n\left(p_{s}=N_{d}\right)$ for $N_{\mathrm{d}}=8 \times 10^{15} \mathrm{~cm}^{-3}(0.3 \Omega$-cm resistivity of the substrate), or as an asymmetrical $p^{+}-n$ junctions $\left(p_{s} \geq 10 N_{d}\right)$ for $N_{\mathrm{d}}=8 \times 10^{14} \mathrm{~cm}^{-3}(5 \Omega-$ $\mathrm{cm}$ resistivity of the substrate). Due to the substrate resistivity used in this work, $10 \Omega-\mathrm{cm}$ $\left(N_{\mathrm{d}}=5 \times 10^{14} \mathrm{~cm}^{-3}\right)$, our solar cells with a barrier height of $0.9 \mathrm{eV}$ present an asymmetrical $p^{+}-n$ junctions, and the theoretical analysis of such structures will be conducted based on the theory of $\mathrm{p}^{+-n}$ junctions.

We underline again that the intermediate $\mathrm{SiO}_{x}$ layer formed after the treatment of the silicon substrate in the $\mathrm{H}_{2} \mathrm{O}_{2}$ solution is sufficiently "transparent" for the carriers; then the tunneling current through this layer provides an ohmic contact between the ITO film and the surface-induced $p^{+}$-Si layer.

Thus, we can apply the diffusion theory of the p-n junction based solar cells for modelling the ITO/n-Si solar cells with a barrier height of $0.9 \mathrm{eV}$ (the barrier height does not depend on the substrate carrier concentration) for a silicon substrate resistivity higher than $0.5 \Omega$-cm (or a carrier concentration lower than $8 \times 10^{15} \mathrm{~cm}^{-3}$ ).

\subsection{ITO/n-Si solar cells: design, fabrication and characterization}

The solar cells were fabricated using (100) n-type (phosphorous doped) single-crystalline silicon wafers with a $10 \Omega$-cm resistivity. Both sides of the wafer were polished. Standard wafer cleaning procedure was used. To form the barrier, an $80 \mathrm{~nm}$-thick ITO film with a sheet resistance of $30 \Omega / \square$ was deposited by spray pyrolysis on the silicon substrate treated 
in the $\mathrm{H}_{2} \mathrm{O}_{2}$ solution. This ITO thickness was chosen in order to obtain an effective antireflection action of the film. Metal, as an ohmic contact in the back side of the wafer, was deposited on an $\mathrm{n}^{+}$-layer previously created by diffusion. The device area for measurements was $1-4 \mathrm{~cm}^{2}$. Approximately $1 \mu \mathrm{m}$-thick $\mathrm{Cr} / \mathrm{Cu} / \mathrm{Cr}$ film was evaporated through a metal mask to create a grid pattern (approximately 10 grid-lines $/ \mathrm{cm}$ ). After fabrication, the capacity-voltage characterization was conducted to control the value of the potential barrier. Then the following parameters were measured under AMO and AM1.5 illumination: open circuit voltage $V_{o c}$, short circuit current $I_{s c}$, fill factor FF, and efficiency. No attempt was made to optimize the efficiency of the cells by improving the collection grid. The series resistance $\left(R_{s}\right)$ of the cell was measured using the $R_{s}=\left(V-V_{o c}\right) / I_{s c}$ relationship (Rajkanan, Shewchun, 1979), where $V$ is the voltage from the dark $I-U$ characteristics evaluated at $I=I_{s c}$. It was shown above that the ITO/n-Si heterostructures with a potential barrier height at the silicon surface of $0.9 \mathrm{eV}$ behave as pseudo classical diffusion p-n junctions. Thus, it is expected that the diffusion of holes in the silicon bulk dominates the carrier transport instead of the dominance of the thermo-ionic emission in the Schottky and the metal/tunnel oxide/semiconductor structures. A straightforward measurement of the dependence of the dark current on temperature is, in principle, sufficient to identify a bipolar device in which the thermo-ionic current is negligible in comparison to the minority-carrier diffusion current $\mathrm{J}_{\mathrm{d}}$ (in units of current density). A simple Shockley's analysis of the p-n diode including the temperature dependence of the silicon parameters (diffusion length, diffusion coefficient, minority carrier life-time, and the intrinsic concentration) (Tarr, Pulfrey, 1979) shows that

$$
J_{d}=J_{0 d}[\exp (q V / k T)-1]
$$

and

$$
J_{0 d} \propto T^{\gamma} \exp \left(-E_{g 0} / k T\right),
$$

where $\gamma=2.4$ and $E_{\mathrm{g} 0}=1.20 \mathrm{eV}$.

From Eq.(8) it can be seen that the plot $\log \left(J_{0 \mathrm{~d}} / T \vee\right)$ vs. $1 / T$ should produce a straight line, and that the slope of this line should be the energy $E_{\mathrm{g} 0}$. In the case of MS and MIS devices this slop must be equal to the value of the barrier $\varphi_{\mathrm{b}}$.

Usually, the series resistance of the device affects the $I-V$ characteristics at high forward current densities. To prevent this effect, we must measure the $J_{\mathrm{sc}}$ vs $V_{\text {oc }}$ dependences (Rajkanan, Shewchun, 1979). The photogenerated current is equal to the saturation photocurrent. For minority-carrier MIS diode with a thin insulating layer (Tarr, Pulfrey, 1979)

$$
J_{s c}=J_{r g}\left(V_{o c}\right)+J_{d}\left(V_{o c}\right) .
$$

For an increasing bias, $J_{\mathrm{d}}$ increases faster than the recombination current density $J_{\mathrm{rg}}$; in the high illumination limit we should have

$$
J_{s c}=J_{0 d} \exp \left(q V_{o c} / n k T\right),
$$

which gives an $n$ factor approximately equal to 1 .

Figure 15 shows the measured dependence of $J_{\mathrm{sc}}$ on $V_{\mathrm{oc}}$ at room temperature. The value of $J_{0 \mathrm{~d}}$ in (10) was determined by measuring $J_{\mathrm{sc}}$ and $V_{\mathrm{oc}}$ at different temperatures, and under 
illumination with a tungsten lamp. An optical filter was used to prevent the heating of the cell by the infra-red radiation. For each $J_{\mathrm{sc}}-V_{\mathrm{oc}}$ pair lying in the range where $n \approx 1, J_{0 \mathrm{~d}}=J_{02}$ was calculated from (10). After making the correction for the $T^{\gamma}$ factor appearing in Eq.(8), the $J_{0 \mathrm{~d}}$ values were plotted as a function of the reciprocal temperature, as shown in the insert of Figure 15.

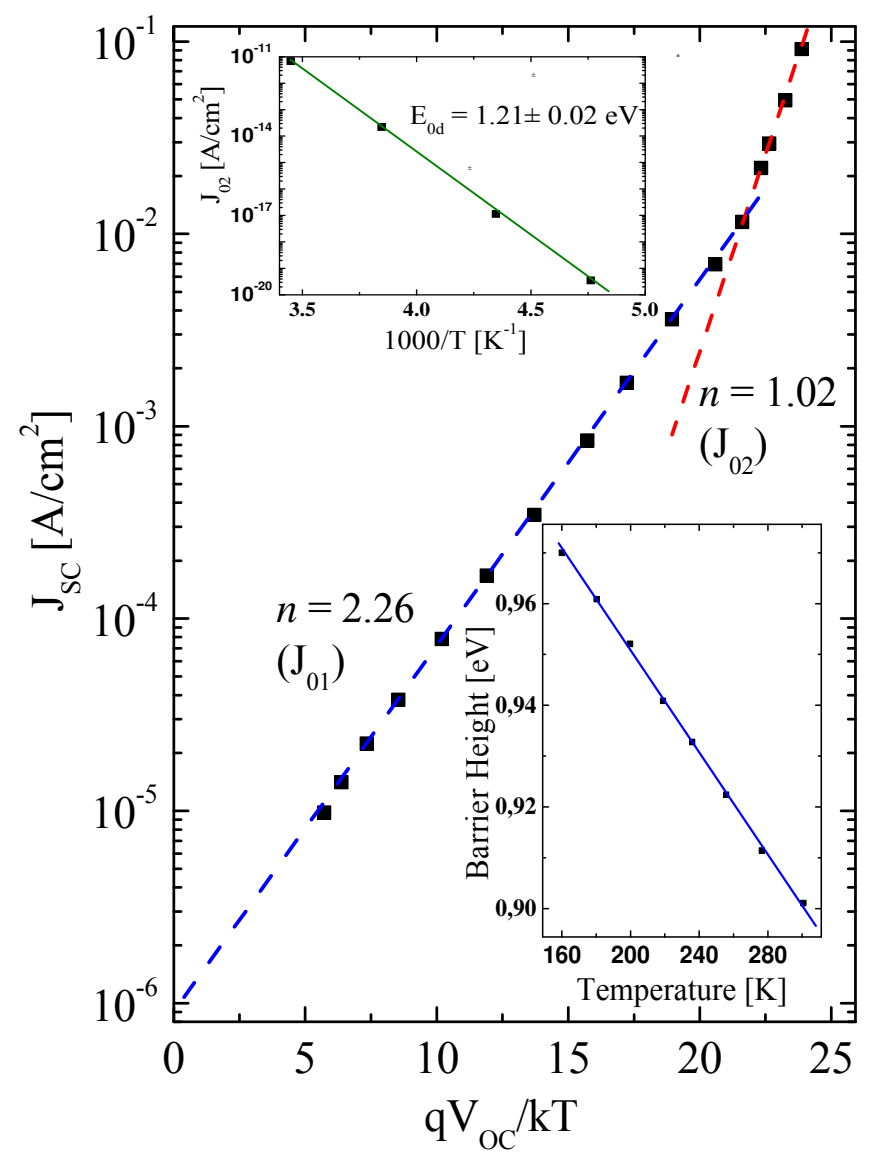

Fig. 15. Measured dependence of $J_{\mathrm{sc}}$ on $V_{\mathrm{oc}}$ at room temperature, and calculated dependence of the current density $J_{02}=J_{0 \mathrm{~d}}$ at high illumination level corrected for the $T^{\gamma}$ factor, as function of reciprocal temperature for ITO/n-Si solar cells with the barrier height of $0.9 \mathrm{eV}$. The dependence of the barrier height on temperature is also shown in the insert

The slope of the $J_{02}$ vs. $1 / T$ line was found to correspond to an energy $E_{\mathrm{g} 0}$ from Eq.(8). It can be concluded that for high current densities the current in the cell is carried almost exclusively by holes injected from the ITO contact that later diffuse into the base of the cell. The output characteristics of the ITO/n-Si solar cell measured under AM0 and AM1.5 illumination conditions, as well as the calculated dependence of output power of the cell versus the photocurrent, are shown in Figure 16. 

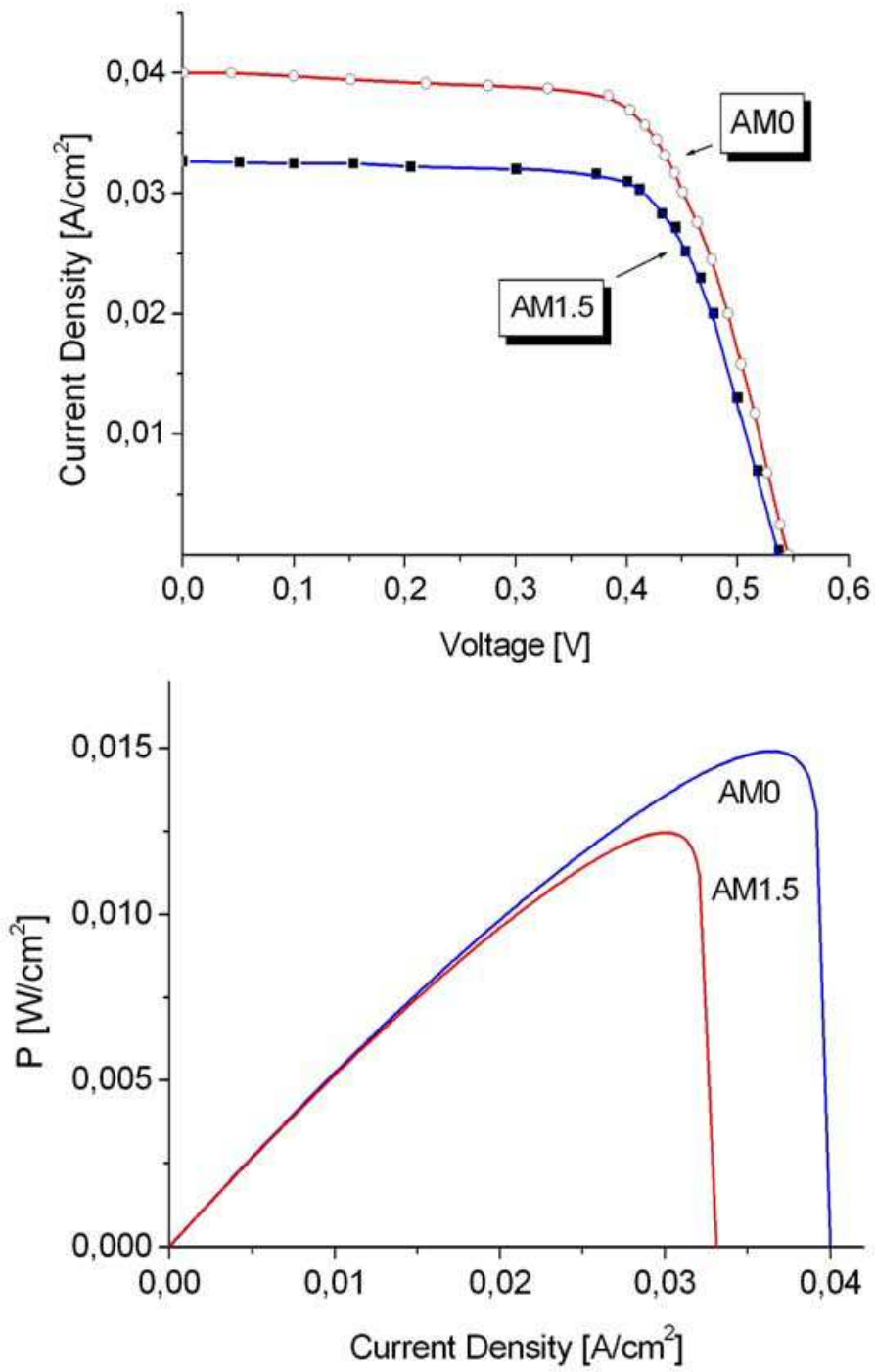

Fig. 16. I- $V$ characteristics (above graph) of the ITO/n-Si solar cell measured under AM0 and AM1.5 illumination conditions, and the calculated dependence of the output power of the cell (below graph) versus the photocurrent

The fill factor (FF) and the efficiency calculated from these characteristics are 0.68 and $10.8 \%$ for AM0 illumination conditions; and 0.68 and 12.1\% for AM1.5 illumination conditions. The fill factor and efficiency obtained are not optimized because of the cell design and the used silicon substrate with relatively high resistivity. Below, a theoretical analysis followed for increasing the output parameters of the cells using silicon substrates with lower resistivity is presented. 


\subsection{Optimization of the output characteristics of the cells: theoretical analysis}

Recently, a detailed theoretical modelling of the ITO/n-Si solar cells has been reported (Malik et al, 2008). Based on these published results, here we show the most important conclusions; further details can be consulted in that work.

For all the calculations, the thickness of the silicon substrate, sheet resistance and thickness of the ITO film were taken as $d=500 \mu \mathrm{m}, 30 \Omega / \square$, and $\mathrm{t}=80 \mathrm{~nm}$, respectively. We considered the case when the diffusion length of minority carriers is shorter than the thickness of the silicon substrate, and assumed that the carrier recombination rate at the back contact of the silicon substrate is infinite. The total series resistance of the cell with an area of $1 \mathrm{~cm}^{2}$ used for these calculations was taken as $1.8 \Omega$.

In order to calculate the theoretical parameters of the solar cells we assumed also that the equation for the $I-V$ characteristic for an illuminated cell (Sze \& Ng, 2007) is

$$
\ln \left(\frac{J+J_{s c}}{J_{0}}-\frac{V-J R_{s}}{J_{0} R_{s h}}+1\right)=\frac{q}{\gamma k T}\left(V-J R_{s}\right),
$$

where $J$ is the current density, $J_{0}$ the saturation dark current density, $J_{\mathrm{sc}}$ is the short-circuit current density, $V$ is the output voltage, $R_{\mathrm{s}}$ and $R_{\mathrm{sh}}$ are the series and shunt resistances, and $\gamma$ is the "ideality" factor of the solar cell. According to our experimental results, $\gamma$ was taken as 1 for the calculations.

In order to calculate the photocurrent density we integrated the next equation based on the spectral distribution of the incident solar radiation, and the parameters of silicon (absorption coefficient $\alpha(\lambda)$, diffusion length for minority carriers $L_{\mathrm{p}}$, and thickness of the silicon substrate $d)$ :

$$
J_{s c}=q \int_{\lambda 1}^{\lambda 2}\left\{(1-R)_{\lambda} F_{\lambda}\left(\frac{\alpha L_{p}}{\alpha^{2} L_{p}^{2}-1} e^{-\alpha W}\right) \times\left(\alpha L_{p}-\frac{\cosh \left(\frac{d}{L_{p}}\right)-e^{-\alpha d}}{\sinh \left(\frac{d}{L_{p}}\right)}\right)+(1-R)_{\lambda} F_{\lambda}\left(1-e^{-\alpha W}\right)\right\} d \lambda
$$

where $q$ is the electron charge, $W$ is the depletion width in the silicon substrate, and $R(\lambda)$ is the spectral reflectance from the ITO/Si interface calculated from the optical constants of silicon and ITO (Malik et al, 2008).

The spectral distribution $F_{\lambda}$ of the solar radiation, which are related to the AM0 (136 $\left.\mathrm{mW} / \mathrm{cm}^{2}\right)$ and AM1.5 $\left(100 \mathrm{~mW} / \mathrm{cm}^{2}\right)$ conditions, have been used in the calculations according to the 2000 ASTME-490-00 and ASTM G-173-03 standards, respectively.

The values of the open-circuit voltage under AM0 and AM1 conditions were calculated according to the equation

$$
V_{o c}=\frac{\gamma k T}{q} \ln \left(\frac{J_{s c}}{J_{0}}+1\right),
$$

where the saturation dark current density $J_{0}$ is calculated from the equation 


$$
J_{0}=q n_{i}^{2} \frac{D_{p}}{N_{d} L_{p}} \operatorname{coth} \frac{d}{L_{p}}
$$

Here, $n_{\mathrm{i}}$ and $N_{\mathrm{d}}$ are the intrinsic and donor concentrations in the silicon substrate, respectively, and $D_{\mathrm{p}}$ is the diffusion coefficient for holes.

Figure 17 shows the experimental (dots) and calculated (lines) $I-V$ characteristics of the solar cell (using equation (11)) with an area of $1 \mathrm{~cm}^{2}$ fabricated on $10 \Omega$-cm silicon under both AM0 and AM1.5 illumination conditions. Initially, these characteristics were calculated using $J_{\mathrm{sc}}=40 \mathrm{~mA} / \mathrm{cm}^{2}, R_{\mathrm{s}}=1.8 \Omega$, and $R_{\mathrm{sh}}=\infty$. Then, in order to improve the fitting with the experimental results, the calculated characteristics were corrected using $R_{\mathrm{sh}}=300 \Omega$. One can see an excellent coincidence between the experimental and calculated characteristics, as well as for the parameters of the cell (fill factor F.F. and conversion efficiency $\eta$ ).

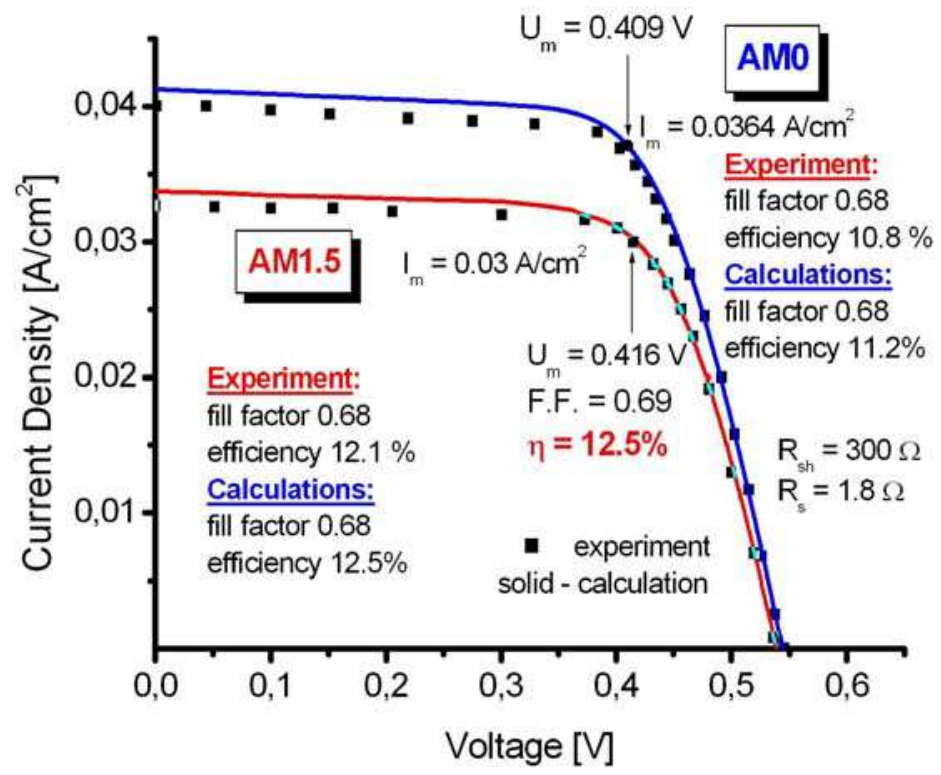

Fig. 17. Experimental (dots) and calculated (solid lines, using equation (11)) $I-V$ characteristics of the solar cell with an area of $1 \mathrm{~cm}^{2}$, and fabricated on a $10 \Omega$-cm silicon substrate, under both AM0 and AM1.5 illumination conditions

Figure 18 (above graph) shows the dependence of the short-circuit current density $J_{\mathrm{sc}}$ on the diffusion length in the silicon substrate, under AM0 and AM1.5 illumination conditions.

The values of the open-circuit voltage under the same conditions were calculated according to equations. (13) and (14). From equation (14), the value of $J_{0}$ decreases with the resistivity $\rho$ of the silicon substrate. The calculated dependence for the open-circuit voltage $\left(\mathrm{V}_{\mathrm{OC}}\right)$ on the resistivity of the Si substrate is also shown in Figure 18 (below graph).

The calculations show that the conversion efficiency of the ITO-SiO ${ }_{x}-n \mathrm{Si}$ solar cells can be improved by using silicon with a lower resistivity. Under the AM1.5 conditions, the calculated dependences of the open circuit voltage, fill factor, and efficiency on the 
resistivity of the silicon substrate, are shown in Figure 19. The surface recombination velocity $\left(S_{\mathrm{p}}\right)$ was taken into account for these calculations. The value of $S_{\mathrm{p}}$ for the ITO/n-Si heterostructures under investigation, and determined from the analysis of the transistor structures, was $500 \mathrm{~cm} / \mathrm{s}$ approximately.
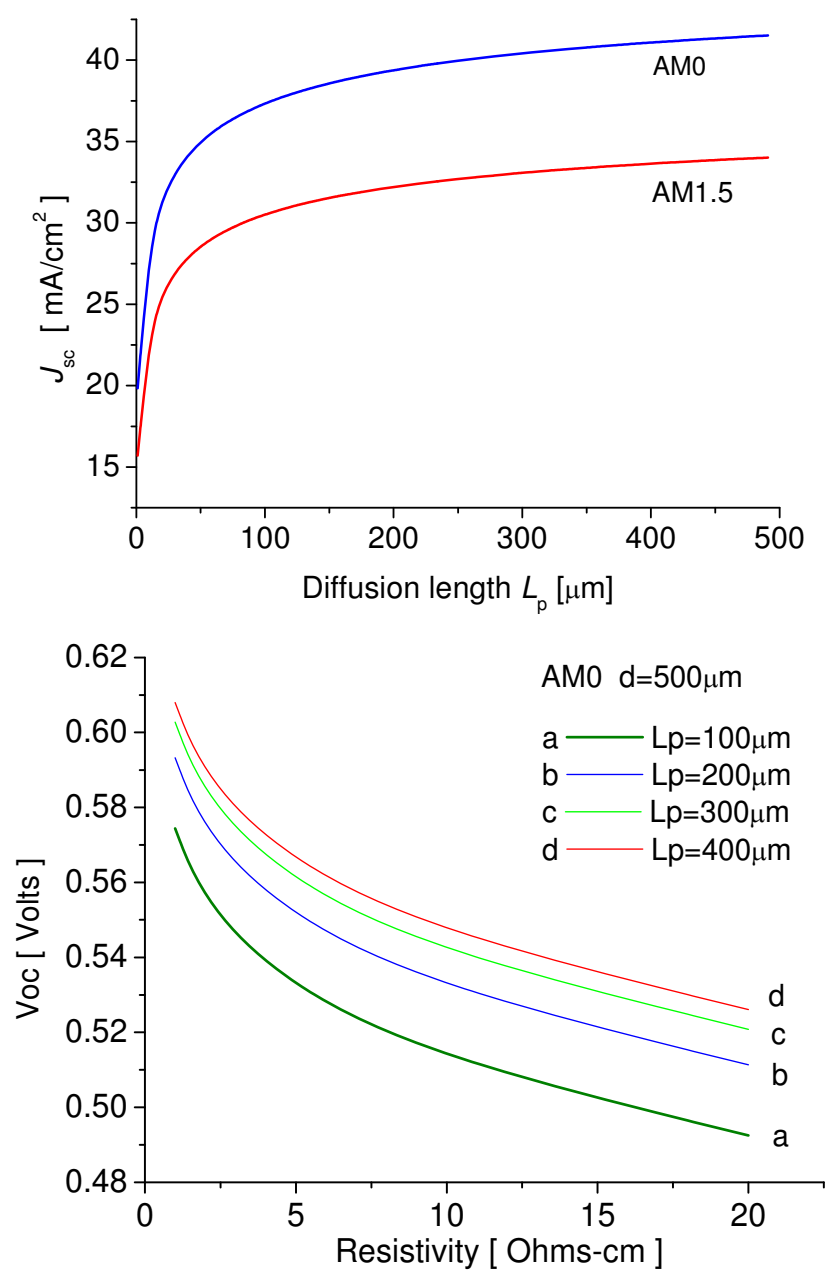

Fig. 18. Calculated dependence of $J_{\mathrm{sc}}$ and $\mathrm{V}_{\mathrm{OC}}$ for the ITO/n-Si solar cells

Solar cells fabricated on silicon substrates with a resistivity of $1 \Omega$-cm and a hole diffusion length of $L_{\mathrm{p}}=200 \mu \mathrm{m}$ may present an efficiency of $14 \%$. For an experimentally found potential barrier of $0.9 \mathrm{eV}$ it is not possible to achieve a further reduction of the silicon resistivity for structures with a $p-n$ inversion layer or minority carrier devices. Such structures are majority carrier devices, and their properties are described by the theory of Schottky barriers. In such cases, a lower efficiency is expected due to a higher saturation current. Solar cells using FTO films present similar characteristics. 


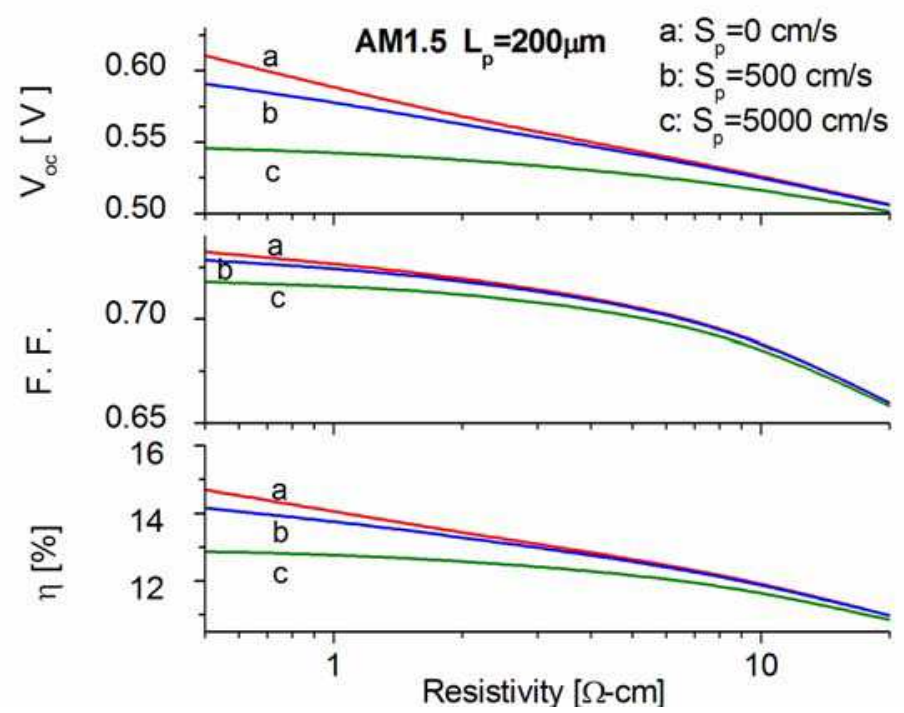

Fig. 19. Calculated dependences of the series resistance, fill factor, and efficiency of the cells, on the resistivity of the silicon substrate.

\section{Conclusions}

ITO-nSi solar cells have been produced using a spraying technique. Transparent and conductive tin-doped indium oxide films, as well as fluorine-doped tin oxide films, presenting excellent structural, optical and electrical parameters, were fabricated using a very simple, low cost, and no-time consuming method. The cells obtained in such a way can be considered as structures presenting an inversion $p-n$ junction. Under the AM0 and AM1.5 solar illumination conditions, the efficiency is $10.8 \%$ and $12.2 \%$, respectively. The theoretical modelling based on $p-n$ solar cells show an excellent coincidence between the theoretical and the experimental results. It is also shown that using $1 \Omega$-cm silicon substrates is a promising alternative for obtaining solar cells with 14\% efficiency under AM1.5 illumination conditions. The use of substrates with a lower resistivity leads to a reduction of the conversion efficiency due to the formation of Schottky barriers, which gives place to a higher saturation dark current than that presented by $p-n$ structures. The fabrication of reported solar cells is more controllable than that needed for obtaining metal-insulatorsilicon solar cells because of the necessity of controlling a very thin (nearly $2 \mathrm{~nm}$ ) intermediate oxide layer on the silicon substrate. Moreover, a detailed theoretical analysis (Shewchun et al., 1980) shows a higher efficiency for p-n inversion solar cells in comparison with those based on majority-carrier MIS structures.

\section{References}

Ashok, S.; Sharma, P. \& Fonash, S. (1980). Spray-deposited ITO-silicon SIS heterojunction solar cells. IEEE Trans. Electron. Dev., Vol.ED-27, N.4, 725-730, ISSN 0018-9383 
Dawar, A. \& Joshi J. (1984). Semiconducting transparent thin films: their properties and applications. J. Mater. Sci., Vol.19, 1-23, ISSN 0022-2461

DuBow, J.; Burk, D. \& Sites, J. (1976). Efficient photovoltaic heterojunctions of indium tin oxides on silicon. Appl. Phys. Lett., Vol.29, N.8, 494-496, ISSN 0003-6951

Feng, T.; Ghosh, A. \& Fishman, G. (1979). Efficient electron-beam-deposited ITO/n-Si solar cells, J. Appl. Phys., Vol.50, N.7, 4972-4974, ISSN 0022-3727

Fukano, T.; Motohiro, T. \& Ida, T. (2005). Ionization potential of transparent conductive indium oxide films covered with a single layer of fluorine-doped tin oxide nanoparticles grown by spray pyrolysis deposition, J. Appl. Phys., Vol.97, N.8, Nanoscale science and design, ISSN 0022-3727

Fujiwara, N.; Fujinaga, T.; Niinobe, D.; Maida, O.; Takahashi, M. \& Kobayashi, H. (2003). Passivation of defect states in $\mathrm{Si}$ and $\mathrm{Si} / \mathrm{SiO}_{2}$ interface states by cyanide treatment: improvement of characteristics of pin-junction amorphous $\mathrm{Si}$ and crystalline Sibased metal-oxide-semiconductor junction solar cells. Acta Phys. Slovaca, Vol.53, N.3, 195-205, ISSN 0323-0465

Granqvist, C. (1993). Transparent Conductive Electrodes for Electrochromic Devices: A Review. Appl. Phys., Vol.A57, 19-24, ISSN 0947-8396

Gouskov, L.; Saurel, J.; Gril, C.; Boustani, M. \& Oemry, A. (1983). Sprayed indium tin oxide layers: Optical parameters in the near-IR and evaluation of performance as a transparent antireflecting and conducting coating on $\mathrm{GaSb}$ or $\mathrm{Ga}_{1-\mathrm{x}} \mathrm{Al}_{\mathrm{x}} \mathrm{Sb}$ for IR photodetection. Thin Solid Films, Vol.99, N.4, 365-369, ISSN 0040-6090

Haacke, J. (1976). New figure of merit for transparent conductors. J. Appl. Phys., Vol.47, 40864089, ISSN 0022-3727

Hamberg, J. \& Granqvist, C. (1986). Evaporated Sn-doped In2O3 films: basic optical properties and applications to energy-efficient windows. J. Appl. Phys., V.60, n.11, R13, ISSN 0022-3727

Hartnagel, H.; Dawar, A.; Jain, A. \& Jagadish, C. (1995). Semiconducting Transparent Thin Films, IOP Publishing Ltd., ISBN 07503 03220, Bristol UK

Malik, A.; Baranyuk, V. \& Manasson, V. (1979). Solar cells based on the $\mathrm{SnO}_{2}-\mathrm{SiO}_{2}-\mathrm{Si}$ heterojunction. Appl. Sol. Energy, N. 2, 83-84, ISSN 0003-701X

Malik, A.; Baranyuk, V. \& Manasson, V. (1980). Improved model of solar cells based on the $\mathrm{In}_{2} \mathrm{O}_{3} / \mathrm{SnO}_{2}-\mathrm{SiO}_{\mathrm{x}}-\mathrm{nSi}$ structure. Appl. Sol. Energy, N.1, 1-2, ISSN 0003-701X

Malik, O.; Grimalsky, V.; Torres-J., A. \& De la Hidalga-W, J. Room Temperature Electroluminescence from Metal Oxide-Silicon. Proceedings of the $16^{\text {th }}$ International Conference on Microelectronics (ICM 2004), pp. 471-474, ISBN 0-7803-8656-6, Tunis, December 06-08, 2004, IEEE, Tunisia

Malik, O.; Grimalsky, V. \& De la Hidalga-W, J. (2006). Spray deposited heavy doped indium oxide films as an efficient hole supplier in silicon light-emitting diodes. J. NonCryst. Sol., Vol.352, 1461-1465, ISSN 0022-3093

Malik, O.; De la Hidalga-W, J.; Zúñiga-I, C. \& Ruiz-T, G. (2008). Efficient ITO-Si solar cells and power modules fabricated with a low temperature technology: results and perspectives. J. Non-Cryst. Sol., Vol.354, 2472-2477, ISSN 0022-3093

Manifacier, J. \& Szepessy, L. (1977). Efficient sprayed $\mathrm{In}_{2} \mathrm{O}_{3}: \mathrm{Sn}$ n-type silicon heterojunction solar cell. Appl. Phys. Lett., Vol.31, N.7, 459-462, ISSN 0003-6951

Manifacier, J.; Fillard, J. \& Bind J. (1981). Deposition of $\mathrm{In}_{2} \mathrm{O}_{3}-\mathrm{SnO}_{2}$ layers on glass substrates using a spraying method. Thin Solid Films, Vol. 77, N.1-3, 67-80, ISSN 0040-6090 
Moholkar, A.; Pawar, S.; Rajpure, K.; \& Bhosale, C. (2007). Effect of solvent ratio on the properties of highly oriented sprayed fluorine-doped tin oxide thin films. Mater. Lett., Vol.61, N.14-15, 3030-3036, ISSN 0167-577X

Nagatomo, T.; Endo, M. \& Omoto, O. (1979). Fabrication and characterization of SnO2/n-Si solar cells, Jpn. J. Appl. Phys., Vol.18, 1103-1109, ISSN 0021-4922

Nagatomo, T.; Inagaki, Y.; Amano, Y. \& Omoto, O. (1982). A comparison of spray deposited ITO/n-Si and SnO2/n-Si solar cells, Jpn. J. Appl. Phys., Vol.21, N. 21-2, 121-124, ISSN 0021-4922

Nakasa, A.; Adachi, M.; Suzuki, E.; Usami, H. \& Fujimatsu, H. (2005). Increase in conductivity and work function of pyrosol indium tin oxide by infrared irradiation, Thin Solid Films, Vol.84, N.1-2, 272-277, ISSN 0040-6090

Nath, P. \& Bunshah, R. (1980). Preparation of $\mathrm{In}_{2} \mathrm{O}_{3}$ and tin-doped $\mathrm{In}_{2} \mathrm{O}_{3}$ films by novel activated reactive evaporation technique. Thin Solid Films, Vol.69, N.1, 63-68, ISSN 0040-6090

Rajkanan, K. \& Shewchun, J.(1979) A better approach to the evaluation of the series resistance of solar cells, Sol. St. Electron., Vol.22, N.2-E, 193-197, ISSN 0038-1101

Saxena, A.; Singh, S.; Thangaraj, R. \& Agnihotri O. (1984). Thickness dependence of the electrical and structural properties of $\mathrm{In}_{2} \mathrm{O}_{3}:$ Sn films, Thin Solid Films, Vol.117, N.2, 95-100, ISSN 0040-6090

Shewchun, J.; Burc, D. \& Spitzer, M. (1980). MIS and SIS solar cells, IEEE Trans. Electron. Dev., Vol.ED-27, N.4, 705-716, ISSN 0018-9383

Song, G.; Ali, M. \& Tao, M. (2008). A high Schottky barrier between Ni and S-passivated ntype Si (100) surface. Sol. St. Electron., Vol.52, 1778-1781, ISSN 0038-1101

Sze, S. \& Ng, K. (2007). Physics of semiconductor devices, $3^{\text {rd }}$ ed., John Wiley and Sons, ISBN 9780471143239, N.Y.

Tarr, N. \& Pulfrey, D. (1979). New experimental evidence for minority-carrier MIS diodes. Appl. Phys. Lett., V.34, N.4, 15 February 1979, 295-297, ISSN 0003-6951

Theuwissen, A. \& Declerck, G. (1984). Optical and electrical properties of reactively d. c. magnetron-sputtered $\mathrm{In}_{2} \mathrm{O}_{3}:$ Sn films. Thin Solid Films, Vol.121, N.2, 109-119, ISSN 0040-6090

Trmop, R.; Hamers, R. \& Demuth, J. (2005). Si (100) dimmer structure observed with scanning tunneling microscopy, Phys. Rev. Lett., Vol.55, N.12, 1303- 1308, ISSN 0031-9007

Vasu, V. \& Snbrahmanyam, A. (1990). Reaction kinetics of the formation of indium tin oxide films grown by spray pyrolysis. Thin Solid Films, Vol.193-194, n.2, 696-703, ISSN 0040-6090

Verhaverbeke, S.; Parker, J. \& McConnell, C. (1997). The role of $\mathrm{HO}_{2}^{-}$: in SC-1 cleaning solutions. In: Mat. Res. Soc. Symp. Proc., Vol. 477: Science and Technology of Semiconductor Surface Preparation, 47-56, MRS, ISBN 1-55899-381-9, N.Y. 


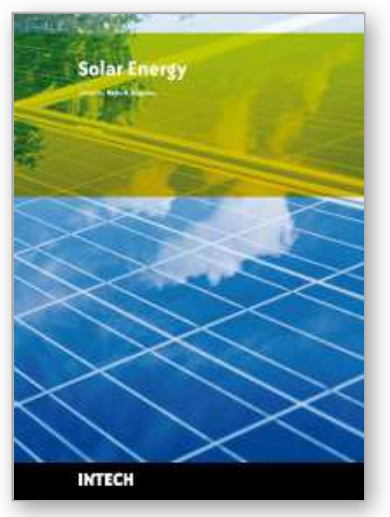

\author{
Solar Energy \\ Edited by Radu D Rugescu
}

ISBN 978-953-307-052-0

Hard cover, 432 pages

Publisher InTech

Published online 01, February, 2010

Published in print edition February, 2010

The present "Solar Energy" science book hopefully opens a series of other first-hand texts in new technologies with practical impact and subsequent interest. They might include the ecological combustion of fossil fuels, space technology in the benefit of local and remote communities, new trends in the development of secure Internet Communications on an interplanetary scale, new breakthroughs in the propulsion technology and others. The editors will be pleased to see that the present book is open to debate and they will wait for the readers' reaction with great interest. Critics and proposals will be equally welcomed.

\title{
How to reference
}

In order to correctly reference this scholarly work, feel free to copy and paste the following:

Oleksandr Malik and F. Javier De la Hidalga-W. (2010). Efficient Silicon Solar Cells Fabricated with a Low Cost Spray Technique, Solar Energy, Radu D Rugescu (Ed.), ISBN: 978-953-307-052-0, InTech, Available from: http://www.intechopen.com/books/solar-energy/efficient-silicon-solar-cells-fabricated-with-a-low-cost-spraytechnique

\section{INTECH}

open science | open minds

\section{InTech Europe}

University Campus STeP Ri

Slavka Krautzeka 83/A

51000 Rijeka, Croatia

Phone: +385 (51) 770447

Fax: +385 (51) 686166

www.intechopen.com

\section{InTech China}

Unit 405, Office Block, Hotel Equatorial Shanghai

No.65, Yan An Road (West), Shanghai, 200040, China

中国上海市延安西路65号上海国际贵都大饭店办公楼405单元

Phone: +86-21-62489820

Fax: +86-21-62489821 
(C) 2010 The Author(s). Licensee IntechOpen. This chapter is distributed under the terms of the Creative Commons Attribution-NonCommercialShareAlike-3.0 License, which permits use, distribution and reproduction for non-commercial purposes, provided the original is properly cited and derivative works building on this content are distributed under the same license. 